\title{
UWB ANTENNA DESIGN USING GRAVITATIONAL SEARCH ALGORITHM
}

\author{
K. R. Mahmoud \\ Electronics \& Communications Department, Faculty of Engineering, Helwan University, Egypt. \\ Kurany_hameda@h-eng.helwan.edu.eg
}

Received 5 June 2013; accepted 23 August 2013

\begin{abstract}
In this paper, a heuristic search method called Gravitational Search Algorithm (GSA) is proposed to design Ultra-wideband antennas (UWB) with irregular shape radiators. To measure the algorithm efficiency in practical antennas design, the results are compared with those obtained using the Central Force Optimization (CFO) technique. The optimization algorithms in MATLAB code are linked to Finite Element Method (FEM) solution technique (Ansoft HFSSsoftware) to simulate the antenna. The optimized compact antennas are fed by a microstrip line and built on an FR-4 substrate with $30 \times 30 \mathrm{~mm}^{2}$ surface area and $1.5 \mathrm{~mm}$ thickness. The radiation characteristics of the designed antennas are completely analyzed, and the VSWR is then compared with the measurements to check the validity of the numerical results.

Keywords: UWB Antenna, Central Force Optimization (CFO), Gravitational Search Algorithm (GSA).
\end{abstract}

\section{Introduction}

Ultra-wideband (UWB) technology has inspired many researchers and industrialists since the Federal Communication Commission (FCC) announced the use of unlicensed frequency band of 3.1-10.6 GHz for commercial communication applications in 2002 [1]. This available wide bandwidth enables UWB systems to achieve high speed and high data rates in communications applications. The antenna is considered an important component in the UWB system, and it affects the overall performance of the system. Many UWB antennas were designed using planar structure due to advantages of low profile, low cost, light weight, and easy fabrication. The dimensions and geometry of the radiator largely affect the impedance matching. To achieve the design goal, various types of planar UWB antennas have been developed with many various shaped planar elements, such as rectangular, circular, triangular, elliptical, pentagonal and octagonal geometries as radiators [2-7]. Other studies used a simple stepped-shape patch and ground structure [8]. However, those shapes have uniform or smooth edges on the radiator and the dimensions of the radiator were determined by experimental efforts. Nowadays, heuristic nature-inspired techniques such as Genetic Algorithms (GA), Particle Swarm Optimization (PSO), Bacterial Swarm Optimization (BSO), and Central Force Optimization (CFO) have become standard procedures for designing optimized antennas [9-10]. In [11], an irregular shape radiator for UWB applications has been designed by PSO taking into account a predefined shape with unknown dimensions.

Journal of Engineering Sciences, Assiut University, Faculty of Engineering, Vol. 41, No. 5, September, 2013, E-mail address: jes@aun.edu.eg 
K. R. Mahmoud, UWB Antenna Design Using Gravitational Search Algorithm, pp. 1890 - 1903

Recently, Gravitational Search Algorithm (GSA) is considered as a new optimization technique based on the law of gravity and mass interaction [12]. A set of various standard benchmark functions were examined and in most cases the GSA provided superior or at least comparable results with Real Genetic Algorithm (RGA), PSO and CFO. In [13], a comparative performance of gravitational search algorithm and modified particle swarm optimization algorithm for synthesis of thinned scanned concentric ring array antenna is considered. It is found that, the GSA technique has better performance than the modified PSO algorithm in terms of computed final fitness values and computational time. In [14], a fully digital controlled reconfigurable concentric ring array antenna has been proposed using GSA. Results clearly showed a very good agreement between the desired and GSA synthesized pattern even with a 4bit digital attenuator and a 5-bit digital phase shifter instead of a continuous phase shifter and an analog attenuator. In [15], GSA has been applied for the length and width calculations of the rectangular patch antenna under various resonant frequencies, substrate permittivity and thickness of the antenna. However in [15] a simple microstrip antenna using an equivalent transmission line model is considered.

In this paper, the GSA combined with the finite element method based simulator, HFSS, is considered to design and optimize UWB antennas with an irregular radiator shape. The antenna parameters such as return loss, radiation patterns, antenna gain, and radiation efficiency are discussed. The antenna is analyzed completely using HFSS which linked with MATLAB to optimize the antenna via Visual Basic for Applications (VBA) program. Interchanging information between Microwave Studio (MWS) and MATLAB allows the implementation of optimization algorithms not included in the MWS environment itself [16]. The main advantage of the proposed approach is that it reduces the time required to solve an electromagnetic problem with better results.

The paper is organized as follows; In Section 2 an introduction to GSA optimization technique is introduced. In Section 3 problem formulation is described. In Section 4, the numerical results are presented and compared with the measured results. Finally, the conclusions are given in Section 5.

\section{Gravitational Search Algorithm Optimization Technique}

The Gravitational Search Algorithm (GSA) is a new meta-heuristic optimization algorithm motivated by the Newton's laws of gravity and motion as proposed by Rashedi in 2007 [12]. According to this algorithm, agents are considered as objects and their performance is measured by their masses. Every object attracts every other object with gravitational force. Each agent in GSA is specified by four parameters: position of the mass in $d$-th dimension, inertia mass, active gravitational mass and passive gravitational mass. The positions of the mass of an agent at specified dimensions represent a solution of the problem and the inertia mass of an agent reflect its resistance to make its movement slow. Both the gravitational mass and the inertial mass, which control the velocity of an agent in specified dimension, are computed by fitness evolution of the problem. The GSA algorithm can be described as follows:

Journal of Engineering Sciences, Assiut University, Faculty of Engineering, Vol. 41, No. 5, September, 2013, E-mail address: jes@aun.edu.eg 
K. R. Mahmoud, UWB Antenna Design Using Gravitational Search Algorithm, pp. 1890 - 1903

\section{Step 1: Initialization}

Randomly, initialize the positions of $\mathrm{N}$ agents within the given search space, $i$-th object is defined by:

$$
X_{i}=\left(x_{i}^{1}, \ldots \ldots \ldots, x_{i}^{d}, \ldots \ldots \ldots, x_{i}^{n}\right)
$$

where, $x_{i}^{d}$ represents the positions of the $i$-th agent in the $d$-th dimension and $n$ is the space dimension.

\section{Step 2: Fitness Evaluation of All Agents}

Perform the fitness evolution for all agents at each iteration and also compute the best and worst fitness at each iteration defined as below:

$$
\begin{aligned}
& \operatorname{best}(t)=\min _{j \in\{1, \ldots, N\}} f i t_{j}(t) \\
& \operatorname{worst}(t)=\max _{j \in\{1, \ldots, N\}} f i t_{j}(t)
\end{aligned}
$$

where, fit $_{j}(t)$ represents the fitness of the $j$-th agent at iteration $t$, best $(t)$ and $\operatorname{worst}(t)$ represents the best and worst fitness at generation $t$ for minimization problems.

\section{Step 3: Update Gravitational Constant}

In GSA, the gravitational constant, $G$, will take an initial value, $G_{0}$, and it will be reduced with time using the following equation:

$$
\left.G(t)=G_{0} e^{\left(\frac{\alpha t}{i t e r} \max \right.}\right)
$$

where $G_{0}$ is set to $100, \alpha$ is set to 20 and iter $_{\max }$ is the maximum iteration number [12].

\section{Step 4: Calculate the Agents' Masses}

According to [12] mass of each agent is computed after calculating current population's fitness as:

$$
M_{i}(t)=\frac{m_{i}(t)}{\sum_{j=1}^{N} m_{i}(t)}
$$

where, $M_{i}(t)$ is the mass value of the agent $i$ at time $t$.

$$
m_{i}(t)=\frac{\text { fit }_{i}(t)-\text { worst }(t)}{\text { best }(t) \text {-worst }(t)}
$$

\section{Step 5: Calculate the Agents' Accelerations}

To calculate the acceleration of each agent $i$ at iteration $t$, the force acting on the $i$-th mass from the $j$-th mass at $d$-th dimension and $t$-th iteration will be calculated according to Newton gravitation theory as below:

$$
F_{i j}^{d}(\mathrm{t})=G(t) \frac{M_{p i}(t) M_{a j}(t)}{\left\|X_{i}(t), X_{j}(t)\right\|_{2}+\varepsilon}\left(x_{j}^{d}(t)-x_{i}^{d}(t)\right)
$$

where, $M_{a j}$ is the active gravitational mass related to agent $j, M_{p i}$ is the passive gravitational mass related to agent $i .\left\|X_{i}(t), X_{j}(t)\right\|_{2}$ is the Euclidian distance between two agents ' $i$ ' and ' $j$ ' at iteration $t$ and $G(t)$ is the computed gravitational constant at time $t . \varepsilon$ is a small constant [12].

The accelerations of the $i$-th agents at iteration $t$ is computed as below:

$$
a_{i}^{d}(\mathrm{t})=\frac{F_{i}^{d}(t)}{M_{i i}(t)}
$$

Journal of Engineering Sciences, Assiut University, Faculty of Engineering, Vol. 41, No. 5, September, 2013, E-mail address: jes@aun.edu.eg 
K. R. Mahmoud, UWB Antenna Design Using Gravitational Search Algorithm, pp. 1890 - 1903

where, $F_{i}^{d}(\mathrm{t})$ is the total force acting on $i$-th agent calculated as:

$$
F_{i}^{d}(\mathrm{t})=\sum_{i \neq j} \operatorname{rand}_{j} F_{i j}^{d}(t)
$$

where rand $_{j}$ are a random numbers in the interval $[0,1]$.

\section{Step 6: Update the Velocity and Position of Each Agent}

Now, the velocity and position of each agent can be calculated using the following equations, respectively.

$$
\begin{aligned}
& v_{i}^{d}(t+1)=\operatorname{rand}_{i} v_{i}^{d}(t)+a_{i}^{d}(t) \\
& x_{i}^{d}(t+1)=x_{i}^{d}(t)+v_{i}^{d}(t+1)
\end{aligned}
$$

where $x_{i}^{d}$, and $v_{i}^{d}$ represent the position, and velocity of $i$-th agent in $d$-th dimension, respectively. rand $_{i}$ are uniform random variables in the interval $[0,1]$. These random numbers are applied to give randomized characteristics to the search.

\section{Step 7: Repetition}

Repeat from Steps 2 to 6 are repeated until iterations reach their maximum limit. Return the best fitness computed at final iteration as a global fitness of the problem and the positions of the corresponding agent at specified dimensions as the global solution of that problem. Figure 1 shows the flowchart of the GSA algorithm. For the sake of brevity, the detailed concepts of CFO are excluded here where it is completely described before in [10].

Based on the theoretical comparison of GSA and CFO, we compared CFO and GSA in low-dimensional problem of ten variables. Since CFO searches for maxima, the negative of the functions is tested for CFO. In CFO, the position vector array is filled with random initialization of probes such as GSA. For both algorithms, the number of agents and the maximum number of iterations are set to 10 and 50, respectively.

\section{Problem Formulation}

Fig. 2 shows the antenna geometry with a random radiator shape to formulate the problem. The antenna is fed by $50 \Omega$ microstrip line with fixed width ( $W_{f}=3 \mathrm{~mm}$ ) and length $\left(L_{f}=12.5 \mathrm{~mm}\right)$. The proposed antenna is to be fabricated on an FR-4 substrate with $30 \times 30 \mathrm{~mm}^{2}$ surface area, $1.5 \mathrm{~mm}$ thickness with a relative permittivity of 4.4 and loss tangent of 0.02 . There is no ground metallization underneath the radiator for proper operation. The partial ground length $L_{g}=11.5 \mathrm{~mm}$.

As shown in Fig. 2 the radiator shape changes with irregular steps in two directions $x$ and $y$. The steps in $x$-direction are denoted by $x_{1}$ to $x_{5}$ and allowed to be varied from 0.01 to $14.5 \mathrm{~mm}$. However, the steps in $y$-direction are denoted by $\Delta y_{1}$ to $\Delta y_{5}$ and allowed to be varied from 0.01 to $5 \mathrm{~mm}$ taking into account the antenna symmetry around $y$-axis. The right half of the irregular radiator shape is represented as a group of polylines while the left half is a mirror image. The initial coordinate point $P_{0}$ has a fixed value of $x_{0}=W_{f} / 2$ and $y_{0}=L_{f}$. While the coordinates of the polylines $\left(P_{1}, P_{2}, P_{3}, P_{4}\right.$, and $\left.P_{5}\right)$ written in Eq. (12) are arbitrarily adjusted by the optimization

Journal of Engineering Sciences, Assiut University, Faculty of Engineering, Vol. 41, No. 5, September, 2013, E-mail address: jes@aun.edu.eg 
K. R. Mahmoud, UWB Antenna Design Using Gravitational Search Algorithm, pp. 1890 - 1903 techniques such as GSA and CFO. This automated antenna design process will validate various shapes of optimized radiators that can achieve the goal of the design.

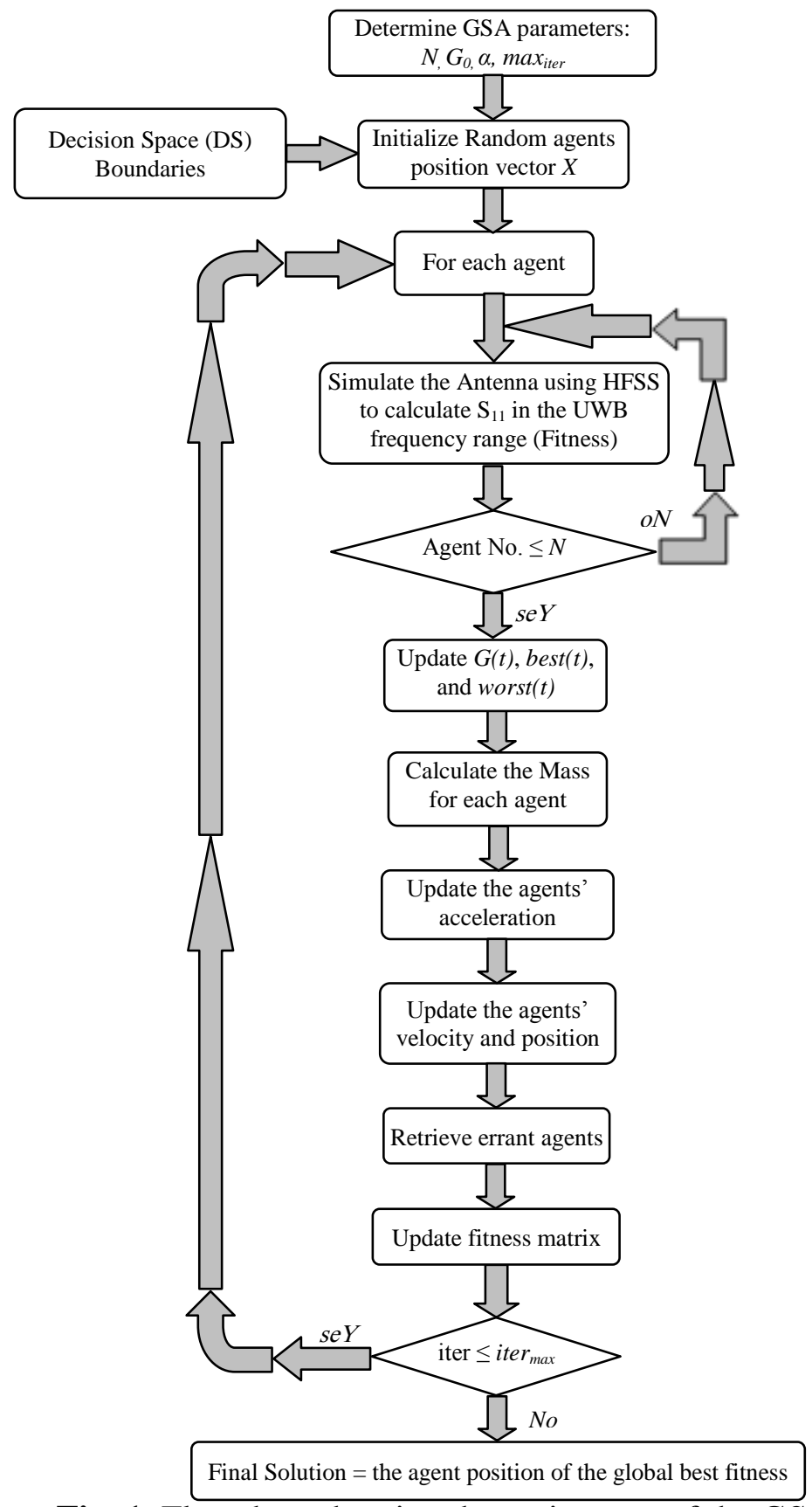

Fig. 1. Flowchart showing the main steps of the GSA algorithm.

Journal of Engineering Sciences, Assiut University, Faculty of Engineering, Vol. 41, No. 5, September, 2013,E-mail address: jes@aun.edu.eg 


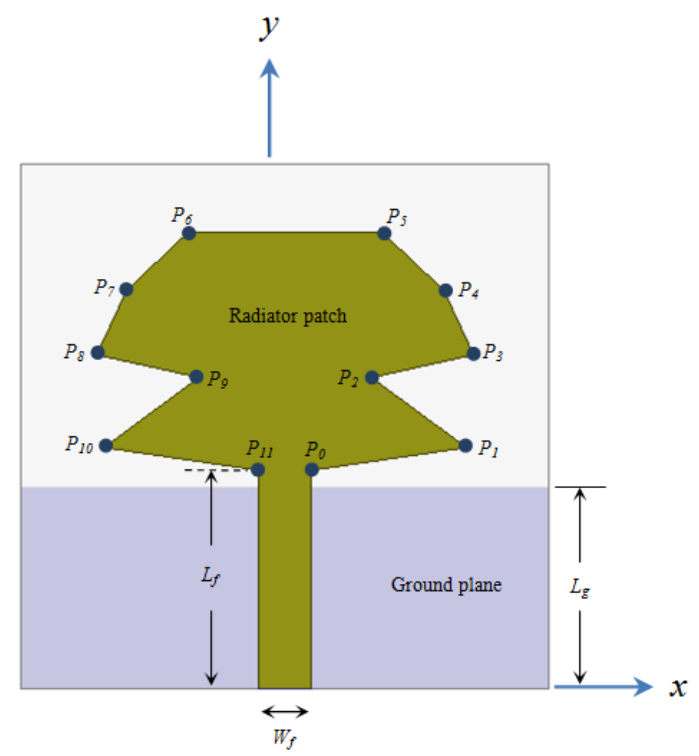

Fig. 2. Initial geometry.

$$
\begin{gathered}
P_{0}=\left(x_{0}, y_{0}\right) \\
P_{1}=\left(x_{1}, y_{0}+\Delta y_{1}\right) \\
P_{2}=\left(x_{2}, y_{0}+\Delta y_{1}+\Delta y_{2}\right) \\
P_{3}=\left(x_{3}, y_{0}+\Delta y_{1}+\Delta y_{2}+\Delta y_{3}\right) \\
P_{4}=\left(x_{4}, y_{0}+\Delta y_{1}+\Delta y_{2}+\Delta y_{3}+\Delta y_{4}\right) \\
P_{5}=\left(x_{5}, y_{0}+\Delta y_{1}+\Delta y_{2}+\Delta y_{3}+\Delta y_{4}+\Delta y_{5}\right) \\
P_{6}=\left(-x_{5}, y_{0}+\Delta y_{1}+\Delta y_{2}+\Delta y_{3}+\Delta y_{4}+\Delta y_{5}\right) \\
P_{7}=\left(-x_{4}, y_{0}+\Delta y_{1}+\Delta y_{2}+\Delta y_{3}+\Delta y_{4}\right) \\
P_{8}=\left(-x_{3}, y_{0}+\Delta y_{1}+\Delta y_{2}+\Delta y_{3}\right) \\
P_{9}=\left(-x_{2}, y_{0}+\Delta y_{1}+\Delta y_{2}\right) \\
P_{10}=\left(-x_{1}, y_{0}+\Delta y_{1}\right) \\
P_{11}=\left(-x_{0}, y_{0}\right)
\end{gathered}
$$

Microsoft Visual Basic (VB) script is employed to connect the MATLAB and HFSS simulations in such an iteration that the initial model parameters in the script are simulated in HFSS to get an $S$-matrix, which is sent to the MATLAB to evaluate the fitness function and update the model parameters. Finally the updated model parameters are fed back into HFSS to get a renewed $S$-matrix. This iteration will carry on until the $S$-matrix values meet the set goals or until completing the maximum number of iterations. The goal is set to minimize $S_{11}$ within the frequency range of 3.1 to $10.6 \mathrm{GHz}$ as written in equation (13). The frequency interval is set to $0.1 \mathrm{GHz}$ within the UWB frequency range.

Journal of Engineering Sciences, Assiut University, Faculty of Engineering, Vol. 41, No. 5, September, 2013, E-mail address: jes@aun.edu.eg 


$$
\text { Fitness }=\min \left(\sum_{3.1 \mathrm{GHZ}}^{10.6 \mathrm{GHz}} S_{11}(f)\right)
$$

The smaller the fitness is, the better optimization result obtained. The reflection coefficient $S_{11}$ of the optimized antenna should be below -10 dB in the UWB spectrum.

\section{Results and Discussions}

In this paper, five coordinates with ten parameters ( $x_{1}$ to $x_{5}$ and $\Delta y_{1}$ to $\left.\Delta y_{5}\right)$ need to be optimized within their optimization range to achieve the UWB specification. Figures $3 \mathrm{a}$ and $3 \mathrm{~b}$ show the geometries of five UWB antennas their radiators are optimized using GSA and CFO, respectively. Table 1 shows the optimized radiators dimensions for each scenario, and the corresponding impedance bandwidth of simulated $S_{11}$ in addition to the average required processing time either using GSA or CFO algorithm.

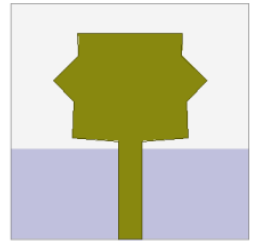

(i)

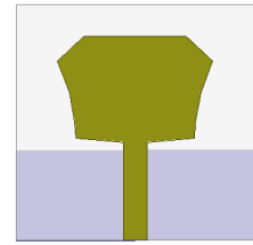

(ii)

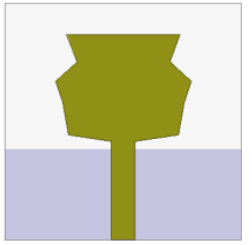

(iii)

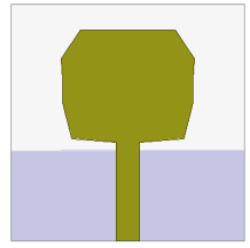

(iv)

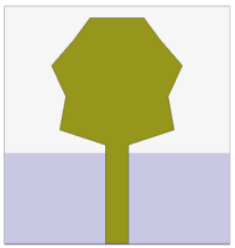

(v)

(a) Optimized UWB antennas using GSA optimization

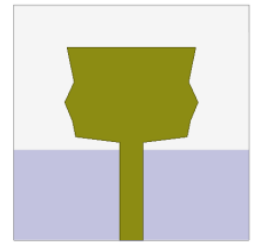

(vi)

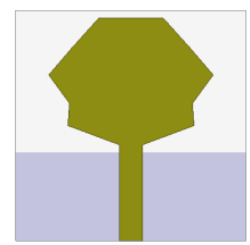

(vii)

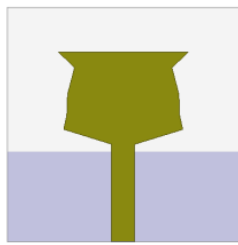

(viii)

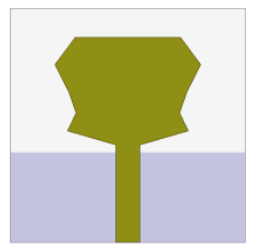

(ix)

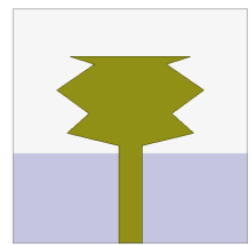

$(\mathrm{x})$

(b) Optimized UWB antennas using CFO algorithm

Fig. 3. Geometries of optimized UWB antennas.

Figures $4 \mathrm{a}$ and $4 \mathrm{~b}$ show the simulated reflection coefficient $S_{11}(\mathrm{~dB})$ of UWB antennas scenarios optimized by GSA and CFO, respectively. It is observed that the different scenarios can cover the UWB spectrum. For example, the optimized antenna in scenario (i) using GSA has a bandwidth of $7.17 \mathrm{GHz}$ starting from $3.47 \mathrm{GHz}$ to 10.64 $\mathrm{GHz}$ compared to a bandwidth of $9.33 \mathrm{GHz}$ starting from $3.5 \mathrm{GHz}$ to $12.83 \mathrm{GHz}$ below $-10 \mathrm{~dB}$ for the optimized antenna (scenario vi) using CFO.

Journal of Engineering Sciences, Assiut University, Faculty of Engineering, Vol. 41, No. 5, September, 2013, E-mail address: jes@aun.edu.eg 
K. R. Mahmoud, UWB Antenna Design Using Gravitational Search Algorithm, pp. 1890 - 1903

Table 1.

The optimized dimensions of UWB antennas

\begin{tabular}{|c|c|c|c|c|c|c|c|c|c|c|c|}
\hline \multirow{3}{*}{ Parameters (mm) } & \multirow{3}{*}{ Decision space (mm) } & \multicolumn{10}{|c|}{ Optimum values } \\
\hline & & \multicolumn{5}{|c|}{ GSA } & \multicolumn{5}{|c|}{$\mathrm{CFO}$} \\
\hline & & (i) & (ii) & (iii) & (iv) & (v) & (vi) & (vii) & (viii) & (ix) & $(\mathrm{x})$ \\
\hline $\mathrm{x}_{1}$ & \multirow{5}{*}{$0.01 \rightarrow 14.5$} & 7.32 & 7.46 & 7.01 & 7.24 & 7.62 & 7.10 & 8.22 & 7.73 & 7.72 & 8.13 \\
\hline $\mathrm{x}_{2}$ & & 7.08 & 7.58 & 7.69 & 8.40 & 6.75 & 7.48 & 8.02 & 7.33 & 6.57 & 5.33 \\
\hline $\mathrm{x}_{3}$ & & 9.67 & 8.32 & 8.60 & 8.42 & 8.68 & 8.53 & 10.69 & 7.23 & 7.54 & 9.42 \\
\hline $\mathrm{x}_{4}$ & & 6.54 & 9.83 & 5.92 & 8.59 & 5.72 & 7.33 & 7.75 & 6.33 & 9.27 & 4.60 \\
\hline $\mathrm{X}_{5}$ & & 6.61 & 6.39 & 7.24 & 6.12 & 3.56 & 8.24 & 4.24 & 8.42 & 6.65 & 7.73 \\
\hline$\Delta \mathrm{y}_{1}$ & \multirow{5}{*}{$0.01 \rightarrow 5$} & 0.41 & 0.47 & 0.84 & 0.53 & 1.90 & 0.73 & 2.47 & 1.91 & 1.78 & 1.64 \\
\hline$\Delta \mathrm{y}_{2}$ & & 4.61 & 2.05 & 4.09 & 4.51 & 4.16 & 1.93 & 2.96 & 1.83 & 2.34 & 2.45 \\
\hline$\Delta \mathrm{y}_{3}$ & & 2.69 & 3.75 & 2.64 & 2.81 & 3.93 & 2.38 & 3.66 & 2.65 & 2.58 & 2.99 \\
\hline$\Delta \mathrm{y}_{4}$ & & 3.16 & 4.02 & 2.49 & 2.71 & 3.25 & 2.68 & 3.51 & 3.41 & 3.54 & 3.35 \\
\hline$\Delta \mathrm{y}_{5}$ & & 2.83 & 3.20 & 3.37 & 3.72 & 2.75 & 4.38 & 3.91 & 2.02 & 3.50 & 0.96 \\
\hline \multicolumn{2}{|c|}{ Bandwidth of simulated $S_{11}(\mathrm{GHz})$} & 7.17 & 7.09 & $>7.56$ & $>7.58$ & 7.77 & $>7.46$ & 7.81 & 6.49 & 7.57 & 7.09 \\
\hline \multicolumn{2}{|c|}{ Average processing time (Hours) } & \multicolumn{5}{|c|}{4.81} & \multicolumn{5}{|c|}{5.28} \\
\hline
\end{tabular}




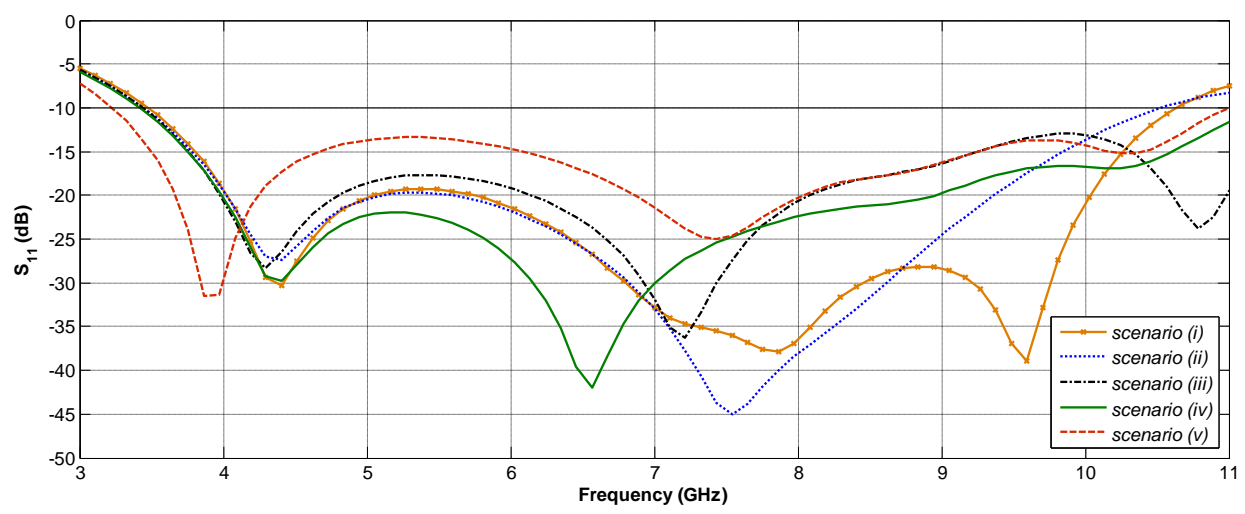

(a) GSA

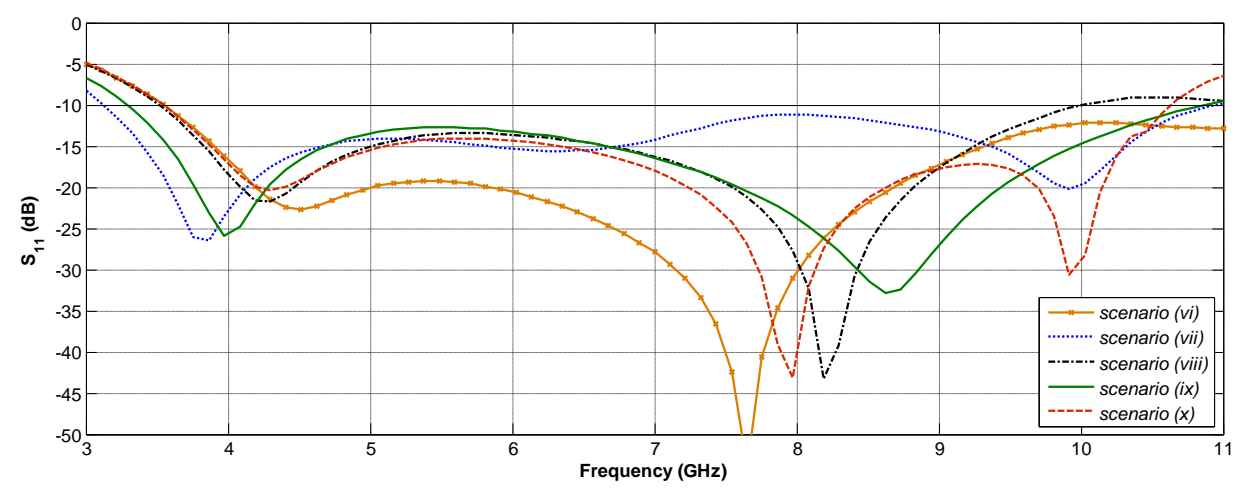

(b) $\mathrm{CFO}$

Fig. 4. The simulated reflection coefficient of optimum UWB antennas.

Figure 5, shows the normalized global best and average fitness of the GSA and CFO algorithms for UWB antenna design. The optimization is executed for 10 independent trials for each algorithm. Comparing the global best fitness of two algorithms, the GSA is found to be faster convergence than the CFO algorithm by $18 \%$. Also, it can be depicted that, the normalized average fitness of GSA technique has a better performance than the CFO algorithm in terms of the computed final fitness values with approximately $4 \%$. As depicted in Table 1 , the average required processing time for GSA run to get the result is about $4.81 \mathrm{hrs}$ compared to $5.28 \mathrm{hrs}$ for CFO on a 64-bit Dell Studio XPS 8100 (Intel $^{\circledR}$ Core $^{\mathrm{TM}}$ Core i7 CPU@ $2.93 \mathrm{GHz}$ ).

Optimized dimensions of the proposed planar UWB antennas (scenarios $i$ and $v i$ ) as presented in Table 1 are fabricated on a cheap FR4 substrate as shown in Figure 6. The antennas have been measured using an Agilent 8719ES network analyzer.

Journal of Engineering Sciences, Assiut University, Faculty of Engineering, Vol. 41, No. 5, September, 2013, E-mail address: jes@aun.edu.eg 


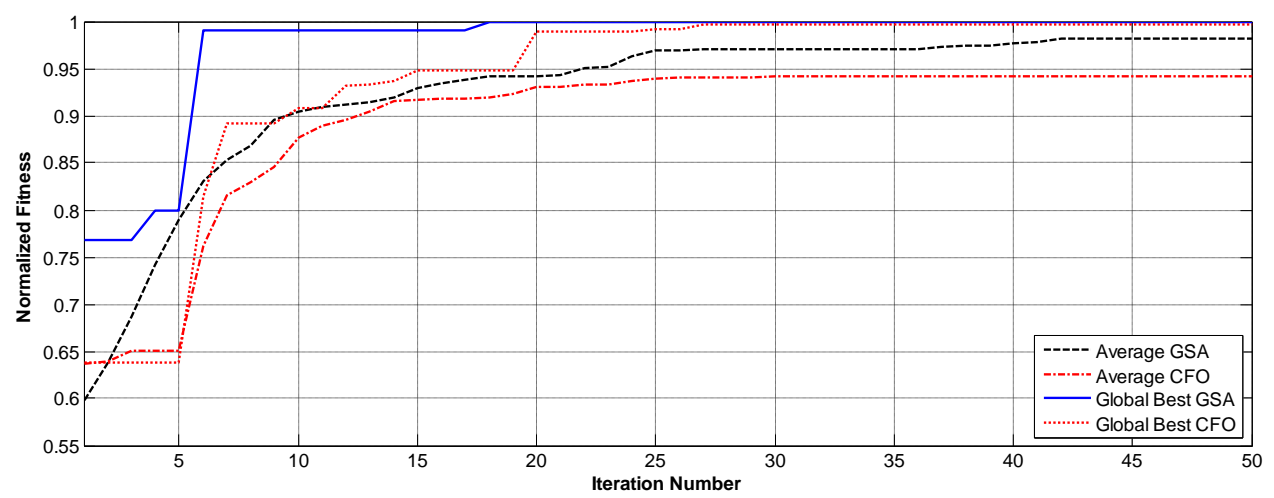

Fig. 5. The normalized global best and average fitness of the GSA and CFO algorithms for UWB antenna design versus the iteration number.

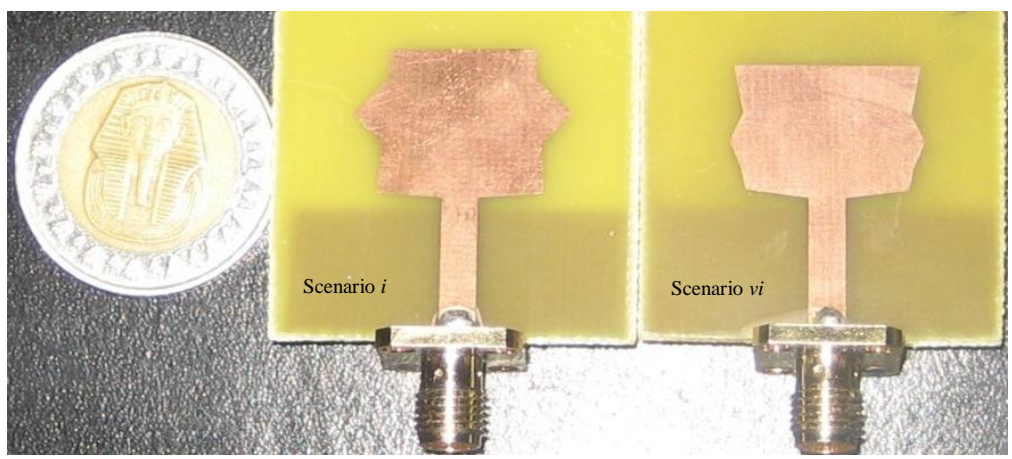

Fig. 6. Photograph of fabricated antennas (scenarios $i$ and $v i$ ).

Figure 7 shows the curves of measured and simulated voltage standing wave ratio (VSWR) of the UWB antennas (scenario $i$ and scenario $v i$ ), a reasonable agreement between simulated VSWR and measured one is observed in the UWB spectrum. The differences between them are attributed to factors such as SMA connector effects, fabrication imperfections, and inappropriate quality of the FR4 substrate.

The radiation patterns of the optimized antennas in $x-z$ and $y-z$ planes at different frequencies of $4 \mathrm{GHz}, 7 \mathrm{GHz}$ and $10 \mathrm{GHz}$ are illustrated in Figure 8. The results showed a nearly omnidirectional pattern in the H-plane and the monopole-like radiation patterns in the E-plane. Figure 9 depicts the simulated peak gain for the optimized antennas $i$ and $v i$. It is found that, an acceptable gain is obtained for both antennas wherein the peak gain of the GSA and CFO optimized antennas are varied from $0.95 \mathrm{~dB}$ to $5.45 \mathrm{~dB}$ and from $0.91 \mathrm{~dB}$ to $5.2 \mathrm{~dB}$, respectively; over the operating frequency range $3.1 \mathrm{GHz}$ to $10.6 \mathrm{GHz}$. The radiation efficiencies of the optimized antennas are illustrated in Figure 10. It is clear that both antennas achieved an

Journal of Engineering Sciences, Assiut University, Faculty of Engineering, Vol. 41, No. 5, September, 2013, E-mail address: jes@aun.edu.eg 
K. R. Mahmoud, UWB Antenna Design Using Gravitational Search Algorithm, pp. 1890 - 1903 acceptable radiation efficiency varied from $95 \%$ to $82 \%$ and from $94.5 \%$ to $87.4 \%$ for GSA and CFO, respectively.

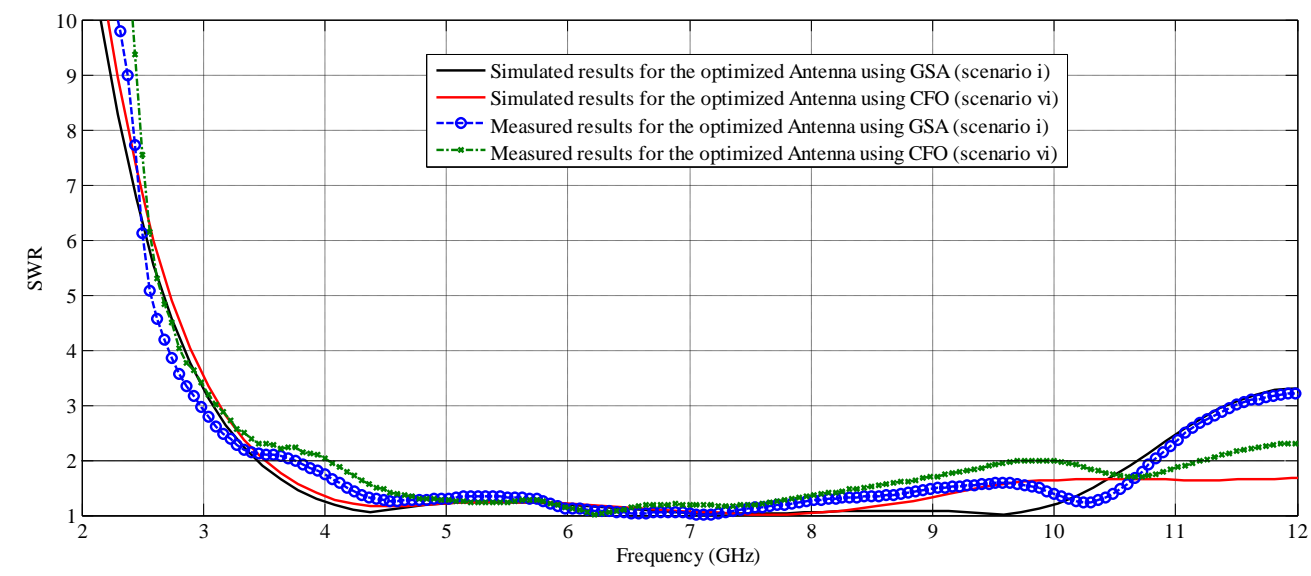

Fig. 7. Measured and simulated VSWR of the UWB antennas (scenario $i$ and scenario $v i)$.

\section{Conclusions}

In this paper, planar UWB antennas with irregular radiator shapes are designed using GSA optimization technique. The GSA optimization combined with the finite element method based simulator, HFSS to design and optimize the proposed antennas. The results are compared with those obtained using CFO algorithm. The proposed approach successfully obtained the desired goal of good properties of bandwidth and radiation pattern in the band of interest. Finally, the comparison between GSA and CFO in the UWB antenna design showed that, the GSA has better performance than the CFO algorithm in terms of computed final fitness values and computational time.

\section{Acknowledgement}

I would like to acknowledge the Electronics Research Institute (ERI), Microstrip Department for the support, encouragement, help and cooperation during simulation and implementation process of this research.

Journal of Engineering Sciences, Assiut University, Faculty of Engineering, Vol. 41, No. 5, September, 2013, E-mail address: jes@aun.edu.eg 


\section{$x-z$ plane}

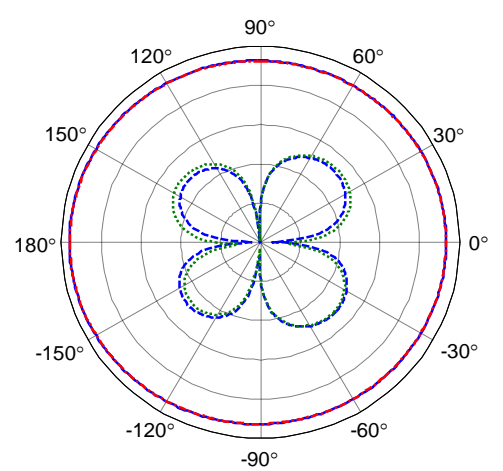

$y$ - $z$ plane

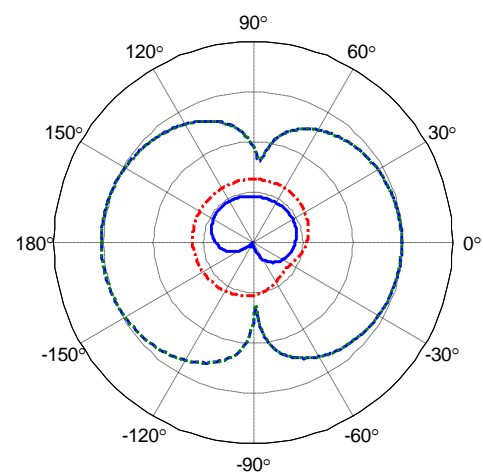

(a) $f=4 \mathrm{GHz}$
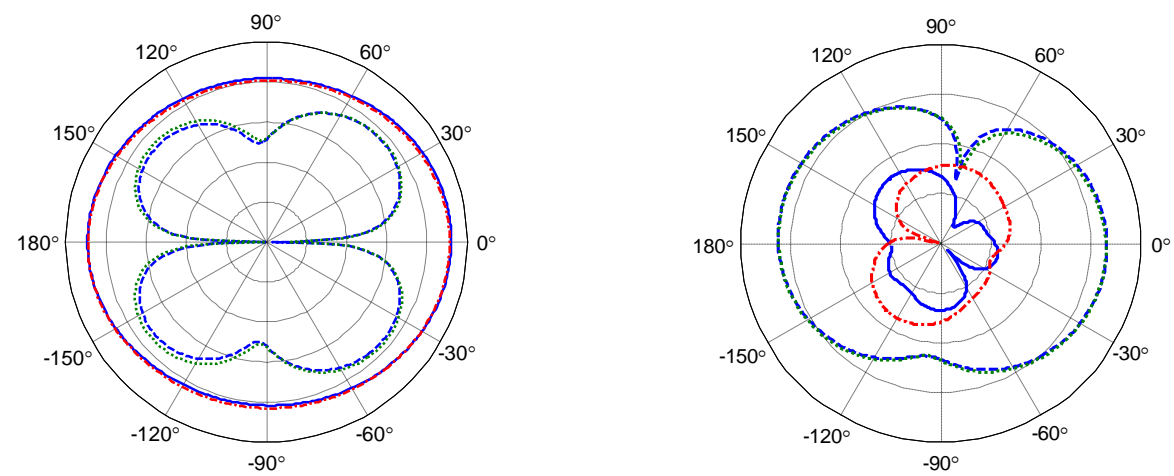

(b) $f=7 \mathrm{GHz}$
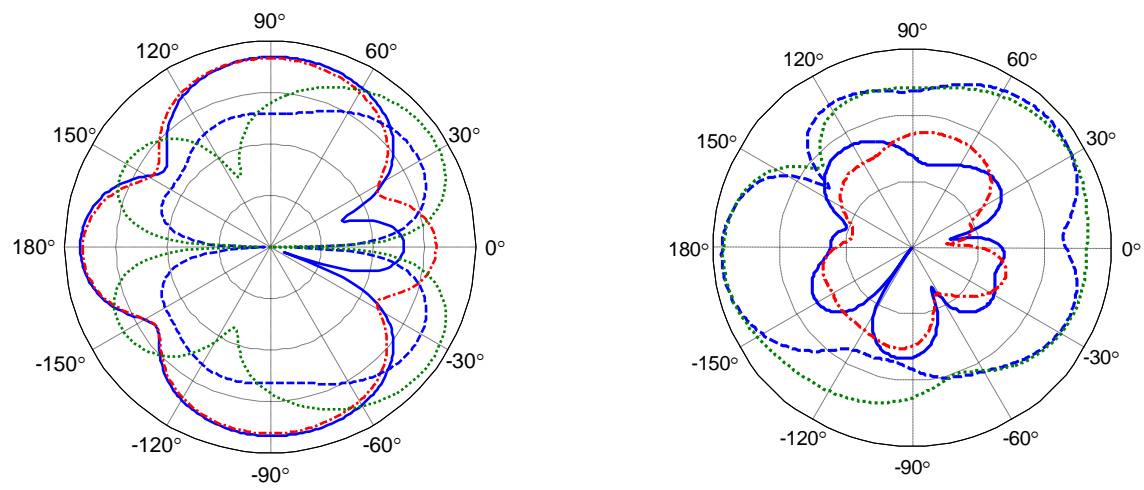

(c) $f=10 \mathrm{GHz}$

Fig. 8. Simulated radiation patterns of the optimized UWB antennas using GSA and CFO in $x z-$ and $y z$ - planes at different frequencies.

$\begin{array}{llll}- & E_{\varphi}(\text { scenario } i) & -\cdots & E_{\varphi}(\text { scenario } v i) \\ \cdots & E_{\theta}(\text { scenario } i) & \cdots \cdots \cdots \cdots \cdots & E_{\theta}(\text { scenario } v i)\end{array}$

Journal of Engineering Sciences, Assiut University, Faculty of Engineering, Vol. 41, No. 5, September, 2013, E-mail address: jes@aun.edu.eg 


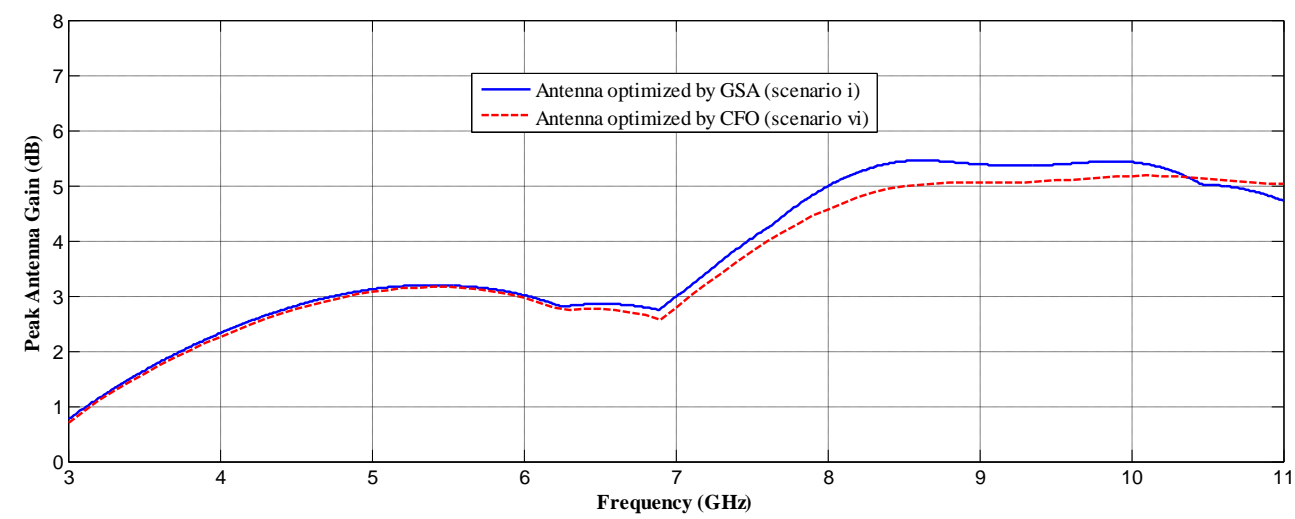

Fig. 9. Simulated peak antenna gain versus frequency of the UWB antennas optimized by GSA and CFO.

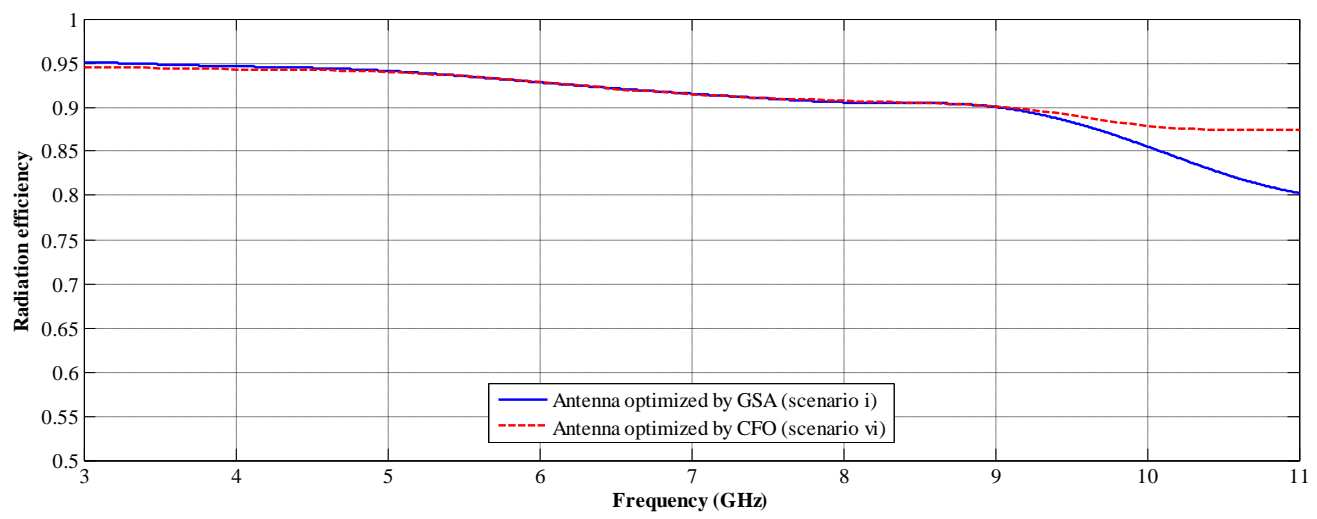

Fig. 10. Simulated radiation efficiency versus frequency of the UWB antennas optimized by GSA and CFO.

\section{References}

[1] Federal Communications Commission, First report and order on ultra-wideband technology, FCC 02-48, Washington, DC, April 22, 2002.

[2] D. H. Kwon, and Y. Kim, "CPW-fed planar ultrawideband antenna with hexagonal radiating elements,” in Proc. IEEE Int. Symp. Antennas Propagation, Vol. 3, 2947-2950, Jun. 2004.

[3] A. Abbosh, and M. Bialkowski, "Design of ultra wideband planar monopole antennas of circular and elliptical shape," IEEE Trans Antennas Propag., Vol. 56, 17-23, 2008.

[4] C.-C. Lin and H.-R. Chuang, "A 3-12 GHz UWB planar triangular monopole antenna with ridged ground-plane,” Progress In Electromagnetics Research, Vol. 83, 307-321, 2008.

Journal of Engineering Sciences, Assiut University, Faculty of Engineering, Vol. 41, No. 5, September, 2013, E-mail address: jes@aun.edu.eg 
K. R. Mahmoud, UWB Antenna Design Using Gravitational Search Algorithm, pp. 1890 - 1903

[5] C. Y. D. Sim, W. T. Chung, and C. H. Lee, "Novel Band-notch UWB Antenna Design with Slit Ground Plane," Microwave Opt. Technol. Lett., Vol. 50, No. 8, 2229-2233, August 2008.

[6] M.A.A. Fattah, A.M.A. Allam, and S.I. Shams, "Irregular pentagon monopole structured antenna for ultra-wideband communication systems," Antennas and Propagation (MECAP), 2010 IEEE Middle East Conference, Cairo, Oct. 20-22, 1-4, 2010.

[7] M. Hayouni, F. Choubani, M. Denden, T.H. Vuong, and J. David, "A Novel Compact Ultra-wideband Rectangular Shaped Antenna,” Progress In Electromagnetics Research Symposium Proceedings, Marrakesh, Morocco, Mar. 20-23, 381-385, 2011.

[8] M. Akbari, M. Koohestani,Ch. Ghobadi, and J. Nourinia, "A new compact planar UWB monopole antenna," Int. J. RF and Microwave CAE, Vol. 21, 216-220, 2011.

[9] K. R. Mahmoud, "Design Optimization of a Bow-Tie Antenna for $2.45 \mathrm{GHz}$ RFID Readers Using a Hybrid BSO-NM Algorithm," Progress In Electromagnetics Research, PIER 100, 105-117, 2010.

[10] K. R. Mahmoud, "Central force optimization: Nelder-Mead hybrid Algorithm for Rectangular Microstrip Antenna Design,” Electromagnetics, Vol. 31, Issue 8, 578-592, 2011.

[11] W.-C. Weng, "Optimal Design of an Ultra-Wideband Antenna with the Irregular Shape on Radiator using Particle Swarm Optimization,” ACES Journal, Vol. 27, No. 5, 427434, May 2012.

[12] E. Rashedi, H. Nezamabadi-Pour, and S. Saryazdi, "GSA: A Gravitational Search Algorithm," Information Sciences, Vol. 179, No. 13, 2232-2248, 2009.

[13] A. Chatterjee, G. K. Mahanti, and N. Pathak, "Comparative performance of gravitational search algorithm and modified particle swarm optimization algorithm for synthesis of thinned scanned concentric ring array antenna," Progress In Electromagnetics Research B, Vol. 25, 331-348, 2010.

[14] A. Chatterjee, G. K. Mahanti, and P. R. S. Mahapatra, "Design of fully digital controlled reconfigurable dual-beam concentric ring array antenna using gravitational search algorithm," Progress In Electromagnetics Research C, Vol. 18, 59-72, 2011.

[15] O.T. Altinoz, and A.E. Yilmaz, "Calculation of optimized parameters of rectangular patch antenna using gravitational search algorithm", INISTA, 2011 International Symposium on Digital Object, 349-353, 15-18 June 2011.

[16] http://www.ansys.com/

\section{تصميم هوائي ذو نطاق عريض جدا (UWB) باستخدام خوارزم جاذبية البحث}

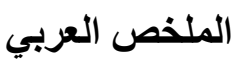

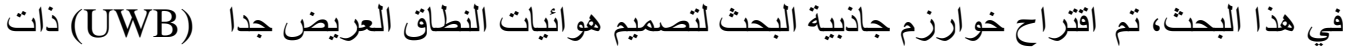

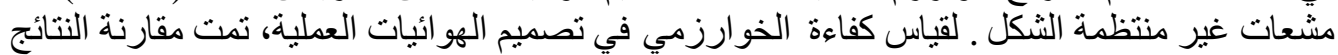
مع تللك التي تم الحصول عليها باستخدام تقنية القوة المركزية المثلى (CFO).

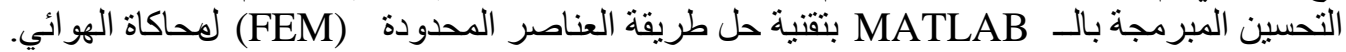

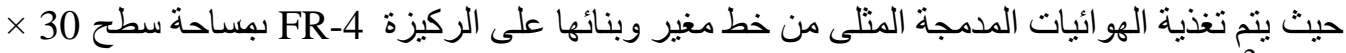

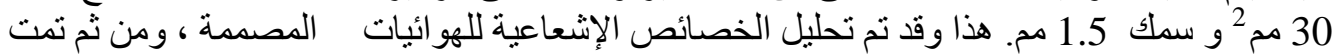

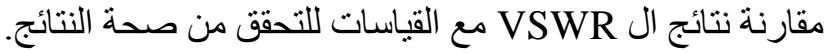

Journal of Engineering Sciences, Assiut University, Faculty of Engineering, Vol. 41, No. 5, September, 2013, E-mail address: jes@aun.edu.eg 